\title{
Integrasi sekolah berbasis peace culture education: program, refleksi, dan implikasi
}

\author{
Yusuf Hanafi ${ }^{1}$, Faris Khoirul Anam ${ }^{2}$, Achmad Sultoni ${ }^{3}$, Titis Thoriquttyas ${ }^{4}$, \\ Muhamamd Saefi ${ }^{5}$, Tsania Nur Diyana ${ }^{6}$, M. Alifudin Ikhsan ${ }^{7 *}$ \\ 1 Universitas Negeri Malang, Malang, Indonesia, email:yusuf.hanafi.fs@um.ac.id \\ 2Universitas Negeri Malang, Malang, Indonesia, email: faris.fs@um.ac.id \\ 3Universitas Negeri Malang, Malang, Indonesia, email: achmad.sultoni.fs@um.ac.id \\ 4Universitas Negeri Malang, Malang, Indonesia, email: titisthoriq.fs@um.ac.id \\ 5Universitas Negeri Malang, Malang, Indonesia, email: muhammadsaefi@gmail.com \\ 6Universitas Negeri Malang, Malang, Indonesia, email: tsanianurdiyana@gmail.com \\ 7Universitas Negeri Malang, Malang, Indonesia, email: um.alifudin93@gmail.com \\ *Koresponden penulis
}

\section{Info Artikel}

Diajukan: 2021-09-06

Diterima: 2022-01-09

Diterbitkan: 2022-01-25

Keywords:

religion; peace culture; school

Kata Kunci:

agama; budaya damai; sekolah
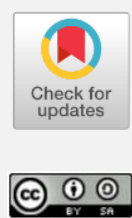

Lisensi: cc-by-sa

Copyright @ 2022 Yusuf Hanafi, Faris Khoirul Anam, Achmad Sultoni, Titis Thoriquttyas, Muhammad Saefi,

Tsania Nur Diyana, M. Alifudin Ikhsan

\begin{abstract}
The community service team at the State University of Malang collaborated with partners from the School Principal Working Meeting (MKKS) Sub Rayon 33 Wagir Malang Regency to launch a PE-based school education program. In detail, this activity was carried out using a participative method with the goal of teaching peace ideals and a spirit of harmony across religious groups, particularly among Wagir District schools of diverse religious types. PE-based education programs are administered through a series of seminar activities and focus group discussions (FGD) to help students understand what they are learning in classroom meetings. This curriculum is divided into two parts: seminar activities that focus on religious moderation and focus groups that focus on its execution. A lot of significant things that may be done in schools and classrooms were created as a result of this exercise, like creating a supportive school climate or culture through respecting other cultures and so on, resolve conflicts, encourage active and collaborative involvement, foster tolerance, and make religious beliefs a guidance for principals, teachers, and students as they carry out their responsibilities at school. The implications of this activity contain at least two important things, namely making schools aware of the importance of peaceful culture education and making students aware of the importance of tolerance towards others.
\end{abstract}

\section{Abstrak}

Tulisan ini mencoba menjelaskan program edukasi sekolah berbasis peace education (PE) yang diprakarsai oleh tim pengabdian kepada masyarakat Universitas Negeri Malang dengan mitra majelis Musyawarah Kerja Kepala Sekolah (MKKS) Sub Rayon 33 Wagir Kabupaten Malang. Secara rinci, kegiatan ini dilaksanakan dengan pendekatan partisipatif yang bertujuan menanamkan nilai-nilai perdamaian dan semangat hidup berdampingan antar umat beragama, khususnya di antara sekolah yang beragam corak keagamaanya di Kecamatan Wagir. Program edukasi berbasis PE dilaksanakan melalui rangkaian kegiatan seminar, focus group discussion (FGD), hingga pelaksanaan langsung kepada siswa dalam pembelajaran di kelas. Program ini dilakukan dalam dua sesi utama, yakni kegiatan seminar dengan pembahasan tentang moderasi beragama dan FGD dengan fokus pada implementasinya. Dari kegiatan ini, dihasilkan sejumlah poin penting yang dapat dilakukan di 
sekolah dan kelas yakni membangun atmosfer atau budaya sekolah yang mendukung dengan mengapresiasi budaya yang berbeda, melakukan resolusi konflik, mendorong partisipasi aktif dan kolaboratif, membangun sikap toleransi, dan membuat nilai-nilai agama menjadi pegangan kepala sekolah, guru, dan siswa dalam menjalankan tugas di sekolah. Implikasi dari kegiatan ini setidaknya memuat dua hal penting yakni menjadikan sekolah sadar atas pentingnya pendidikan budaya damai dan menyadarkan siswa tentang pentingnya sikap toleransi terhadap sesama.

\section{Cara mensitasi artikel:}

Hanafi, Y., Anam, F. K., Sultoni, A., Thoriquttyas, T., Saefi, M., Diyana, T. N., \& Ikhsan, M. A. (2022). Integrasi sekolah berbasis peace culture education: program, refleksi, dan implikasi. Jurnal Inovasi Hasil Pengabdian Masyarakat (JIPEMAS), 5(1), 106-118. https://doi.org/10.33474/jipemas.v5i1.13127

\section{PENDAHULUAN}

Paradigma Peace Education (PE) sangat relevan dan menjanjikan jika diterapkan dengan baik di Indonesia sebagai negara multikultural dan multietnik. Namun pada kenyataannya, Indonesia masih mempunyai kendala besar dalam mewujudkan PE karena pendidikan harus memberikan kesadarakan multikultural seutuhnya kepada siswa sebagai bagian penting dari masyarakat masa depan (Thoyib, 2018). Selama ini, proses pendidikan nampaknya hanya berjalan sebagai agen perubahan pada tataran kognitif, belum menyentuh ranah afeksi siswa, misalnya kecerdasan emosional dan kecerdasan spiritual (Lue \& Riyanto, 2020). Tidak mengherankan jika proses pendidikan ternyata belum dapat menginternalisasi nilai-nilai moral kepada siswa yang dapat mendukung terciptanya perdamaian di tengah masyarakat. Disisi lain, ditemukan sejumlah bukti yang menunjukkan bahwa institusi pendidikan menjadi sumber radikalisme yang dapat menggerus kesadaran multikultural. Sebuah penelitian menunjukkan bahwa sebagian kampus di Indonesia telah terpapar radikalisme (Ibrahim et al., 2018). Menurut laporan penelitian yang dilakukan oleh Ikhsan (2019) diperoleh data bahwa setidaknya 6 dari 10 kampus negeri di Indonesia terindikasi menjadi ladang subur organisasi HTI. Temuan lainnya menunjukkan bahwa kebanyakan dari mereka sudah memiliki "bibit" ekstrim sejak berada di bangku sekolah (Ariyanto et al., 2019). Hal ini dikuatkan dengan hasil penelitian Ikhsan (2019) yang menyatakan bahwa proses terbentuknya radikalisme di lingkungan kampus akibat pola pikir mereka yang tidak toleran terhadap berbagai perbedaan yang terjadi.

Ancaman radikalisme baik dalam bentuk pemikiran maupun aksi semakin meningkat (Hanafi \& Ikhsan, 2019), termasuk dalam pemikiran Islam itu sendiri. Dalam bidang teologi, terdapat beberapa hal yang berpotensi menjadi pemicu munculnya paham radikalisme-takfiri (Llorent-Bedmar et al., 2020). Radikalisme Islam sebagai fenomena historis-sosiologis merupakan masalah yang banyak dibicarakan dalam wacana politik dan peradaban global akibat kekuatan media dalam menciptakan persepsi masyarakat. Kondisi ini tentu akan mempengaruhi gaya berpikir seseorang dalam kerangka kehidupan beragama yang toleran, inklusif dan moderat. Radikalisme pemikiran dan aksi keagamaan jauh lebih berbahaya jika tidak segera ditangani dengan serius. 
Keterlibatan seluruh elemen dalam upaya pencegahan terhadap paham radikalisme sangat dibutuhkan, termasuk dalam lingkup kecil seperti sekolah.

Dalam lingkup lebih sempit, kami mencoba memotret keberagaman corak keagamaan di sejumlah SMP di Kecamatan Wagir Kabupaten Malang, Jawa Timur. Di wilayah ini, setidaknya terdapat sekolah dengan empat corak keagamaan, yakni Islam, Kristen, Hindu dan Katolik. Melihat kondisi ini, kami meyakini bahwa keanekaragaman ini dapat dikelola dengan baik akan mampu membentuk karakter bangsa yang kuat bagi siswa. Di sisi lain, adanya peristiwa tawuran antara siswa SMP beragama Islam dengan siswa beragama Kristen yang terjadi di wilayah ini telah menimbulkan kekhawatiran bahwa keberagaman ini belum diurus dengan baik dan memiliki potensi sebagai sumber konflik sosial berbasis SARA. Peristiwa tawuran ini dipicu oleh saling ejek antar siswa atas dasar perbedaan agama. Hal ini diperparah dengan keikutsertaan guru agama dalam kasus tersebut. Faktor lainnya, tipologi daerah dataran tinggi dan lembah yang menjadikan jarak antara satu sekolah dengan sekolah lain berjauhan merupakan salah satu penyebab sulitnya interaksi dan komunikasi antar siswa.

Berbagai pihak menganggap bahwa kekerasan atas nama agama oleh siswa SMP di atas diakibatkan karena eksrimnya pemahaman siswa dan guru terhadap mata pelajaran Pendidikan Agama Islam di sekolah. Padahal Islam menekankan moderatisme, inklusivitas, dan toleransi yang termaktub dalam AlQuran (Hanafi \& Ikhsan, 2019; Ikhsan, 2017a, 2017b), seperti perlindungan hak asasi manusia, kebebasan beragama, kesetaraan dan peluang yang setara untuk hak asasi manusia dalam masyarakat sipil (Al-Zewairi \& Naymat, 2017). UNESCO (1996) mendefinisikan toleransi sebagai kebajikan yang memungkinkan perdamaian, berkontribusi pada penggantian budaya perang dengan budaya perdamaian. Toleransi adalah harmoni dalam perbedaan, diterjemahkan dalam semboyan negara Indonesia yakni Bhinneka Tunggal lka. Sangat jelas, bahwa toleransi agama Islam sejalan dengan Pancasila, maka dari itu konsep sekoah berbasis budaya pendidikan damai (peace culture education) adalah suatu langkah yang tepat dalam menekan radikalisme di lingkungan sekolah.

Melihat situasi tersebut, konsep PE dan multikulturalisme sebenarnya bukanlah persoalan yang mudah. Banyak hal penting yang harus diperhatikan dalam masyarakat multikultural. Dalam konteks pengabdian masyarakat ini, kami mencoba mengeliminasi terbentuknya kelompok keagamaan yang eksklusif di sekolah dengan menekan pada setiap kepala sekolah untuk mengambil peran baik sebagai fasilitator maupun pengambil kebijakan dalam membantu siswa menuju proses ke arah kedewasaan, saling menghargai perbedaan, seperti perbedaan etnis, budaya, dan agama (Abdullah \& Yani, 2009; Hermawan, 2015).

Kepala Sekolah harus dinilai mampu bersikap lebih moderat dan mengambil kebijakan, memperkuat sosialisasi Pancasila, dan memperjelas pemahaman posisi keagamaan (Ibrahim et al., 2018). Secara halus dapat dilakukan lewat bahasa-bahasa agama yang relevan dan sosialisasi pandangan tentang adanya nilai-nilai afinitas antara agama dan Pancasila, 
dengan harapan dapat mengembalikan corak keagamaan yang jadi ciri khas beragama di Indonesia, yaitu moderat, inklusif, dan toleran (Saidi, 2017). Indonesia memiliki budaya yang luhur gotong royong, dimana sikap kebersamaan dan persatuan dapat ditumbuhkan sebagai modal utama (Ibrahim et al., 2018).

Berdasarkan hasil analisis kebutuhan dengan mitra pengabdian masyarakat dan sekolah lainnya di Kecamatan Wagir, pengabdian masyarakat ini sudah lama ditunggu oleh para pemangku kebijakan khususnya kepala sekolah untuk bersama-sama merumuskan model sekolah berbasis budaya damai di wilayah mereka. Edukasi dan pendampingan sekolah berbasis PE merupakan salah satu ikhtiar untuk memperkuat semangat kebangsaan dan keagamaan di lingkungan sekolah.

\section{METODE PELAKSANAAN}

Untuk menjawab permasalahan mitra di atas, tim ini merumuskan sebuah kegiatan edukasi sekolah berbasis PE yang telah dicetuskan oleh UNESCO sejak 2015. Program kemitraan masyarakat ini dilaksanakan dengan melibatkan delapan SMP target di Kecamatan Wagir Kabupaten Malang, yaitu SMP Negeri 1 Wagir, SMP Negeri 2 Wagir, SMP Kristen Eleos, SMP Tri Murti, SMP Islam Sunan Giri, SMP Islam Diponegoro, SMP PGRI 1 Wagir dan SMP Darul Faqih Indonesia. Mitra kerjasama dalam pengabdian masyarakat ini adalah Majelis MKKS (Musyawarah Kerja Kepala Sekolah) Sub Rayon 33 Wagir Kabupaten Malang.

Adapun partisipan dalam kegiatan edukasi adalah kepala sekolah, wakil kepala sekolah bidang kurikulum, wakil kepala sekolah bidang humas, wakil kepala sekolah bidang kesiswaan, dan kepala tata usaha dari delapan SMP seKecamatan Wagir kabupaten Malang. Diikuti oleh 52 peserta secara tatap muka. Kegiatan edukasi dipusatkan di SMP Darul Faqih Indonesia Desa Pandanlandung Kecamatan Wagir Kabupaten Malang.

Kegiatan edukasi dibagi menjadi tiga fase utama. Sesi pertama dilakukan pemaparan materi tentang moderasi beragama dalam konteks kehidupan berbangsa dan bernegara. Sesi kedua dilakukan dengan focus group discussion (FGD) dengan pembahasan tentang internalisasi PE dalam kehidupan sekolah, khususnya di wilayah Kecamatan Wagir. Dalam sesi kedua ini, terdapat sejumlah fokus pertanyaan yang dibahas, misalnya tentang atmosfer atau budaya sekolah yang dibangun, kebiasaan kepala sekolah/guru dalam mendukung penerapan sekolah berbasis PE, upaya kepala sekolah/guru mengapresiasi budaya yang berbeda, melakukan resolusi konflik, mendorong partisipasi aktif dan kolaboratif, membangun sikap toleransi, menghadapi eksklusivitas di sekolah, dan terakhir tentang bagaimana agama menjadi pegangan kepala sekolah/guru dalam menjalankan tugas di sekolah. Pada Fase ketiga, tim melaksanakan monitoring dan evaluasi serta pendampingan terhadap budaya PE di sekolah. Berikut merupakan diagram alur pelaksanaan kegiatan. 


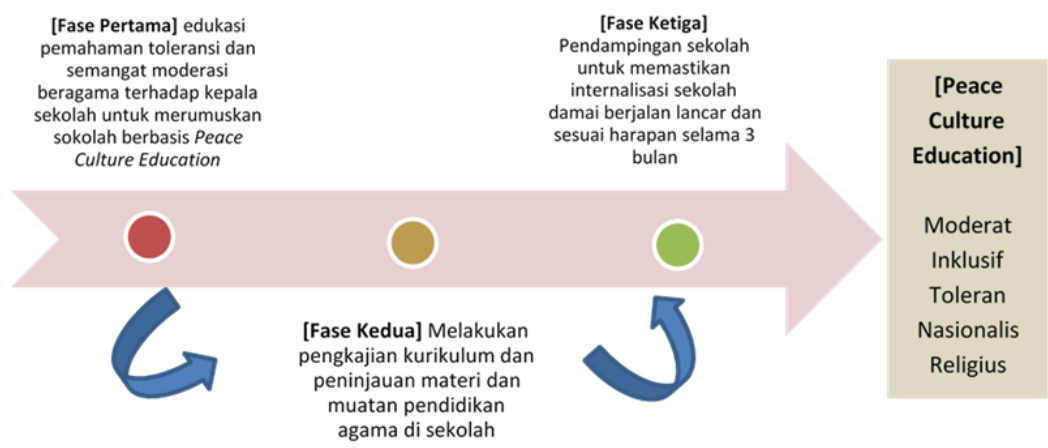

Gambar 1. Diagram alur tahapan pengabdian

\section{HASIL DAN PEMBAHASAN}

Tujuan utama kegiatan edukasi ini adalah untuk memperoleh kesepakatan dalam pemahaman yang utuh dan sama antara kepala sekolah sebagai pengambil kebijakan yang ada di sekolah SMP se-Kecamatan Wagir. Lebih khusus lagi, kegiatan ini berfokus pada melakukan edukasi pemahaman toleransi dan semangat moderasi beragama terhadap kepala sekolah untuk merumuskan kebijakan implementasi sekolah berbasis PE. Kepala sekolah diyakini harus mampu dan memiliki pendirian dan sikap yang lebih moderat dalam menerapkan kebijakan sekolah damai. Karena pendampingan ini dipusatkan di SMP yang berbasis pada pesantren, maka pembahasan mengenai sekolah berbasis PE akan lebih difokuskan dalam konteks agama Islam, dan ini juga bertujuan untuk memberikan pesantren sebagai model pelaksanaan dan merupakan kekayaan budaya dan peradaban muslim Indonesia (Fathurrochman et al., 2019).

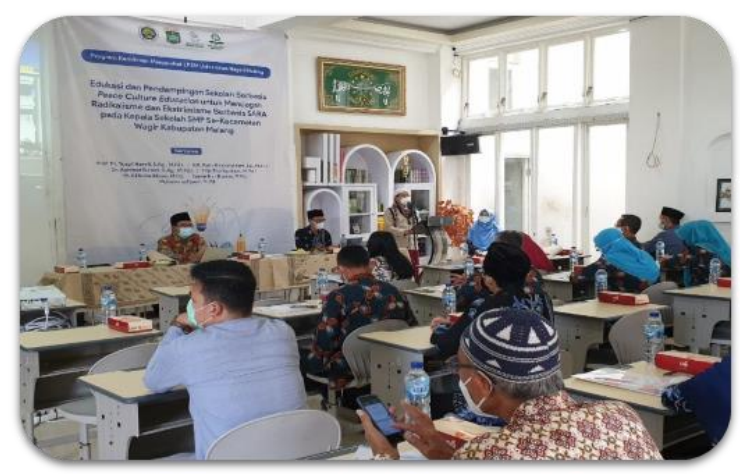

Gambar 2. Para kepala sekolah aktif mengikuti kegiatan

Budaya damai menjadi bagian penting dalam penguatan pendidikan karakter di sekolah (Maskuri et al., 2020). Oleh karena itu, budaya damai penting dalam menginternalisasi nilai-nilai moderasi beragama. Seperti yang telah dijelaskan bahwa SMP yang berada di kecamatan Wagir kabupaten Malang tidak hanya bercorak keagamaan Islam saja, tetapi juga terdapat bercorak nasionalis dan agama non-Islam, misalnya kristen dan Hindu. Dengan 
beragamnya corak keagamaan ini, moderasi beragama menjadi keniscayaan dalam rangka mewujudkan solidaritas, toleransi dan kerukunan umat beragama di lingkungan sekolah. Moderasi beragama telah menjadi pembahasan serius satu dekade terakhir ini sehingga dipilih menjadi materi dalam sesi pertama dalam kegiatan edukasi ini. Pembahasan ini tidak terlepas dari meningkatnya intensitas ujaran kebencian, radikalisme dan ekstrimisme (Ikhsan, 2019; Labiba, 2021).

Ancaman radikalisme baik dalam bentuk pemikiran maupun aksi semakin meningkat (Llorent-Bedmar et al., 2020), termasuk dalam pemikiran Islam itu sendiri (Saidi, 2017). Dalam bidang teologi, terdapat beberapa hal yang berpotensi menjadi pemicu munculnya paham radikalisme-takfiri, seperti hakimiyah dan al-wala wa al-bara. Hal ini nampak pula dalam bidang amaliyah ubudiyah fiqih, babon tasawuf, hingga bidang teologis dan hukum Islam (Abdullah \& Yani, 2009). Radikalisme Islam sebagai fenomena historissosiologis merupakan masalah yang banyak dibicarakan dalam wacana politik dan peradaban global akibat kekuatan media dalam menciptakan persepsi masyarakat. Banyak label yang diberikan untuk menyebut gerakan Islam radikal ini, mulai dari sebutan kelompok garis keras, ekstrimis, militan, Islam kanan, fundamentalis sampai teroris. Kondisi ini tentu akan mempengaruhi gaya berpikir seseorang dalam kerangka kehidupan beragama yang toleran, inklusif dan moderat. Radikalisme pemikiran dan aksi keagamaan jauh lebih berbahaya jika tidak segera ditangani dengan serius (Al-Zewairi \& Naymat, 2017). Keterlibatan seluruh elemen dalam upaya pencegahan terhadap paham radikalisme sangat dibutuhkan (Llorent-Bedmar et al., 2020), termasuk dalam lingkup kecil seperti sekolah.

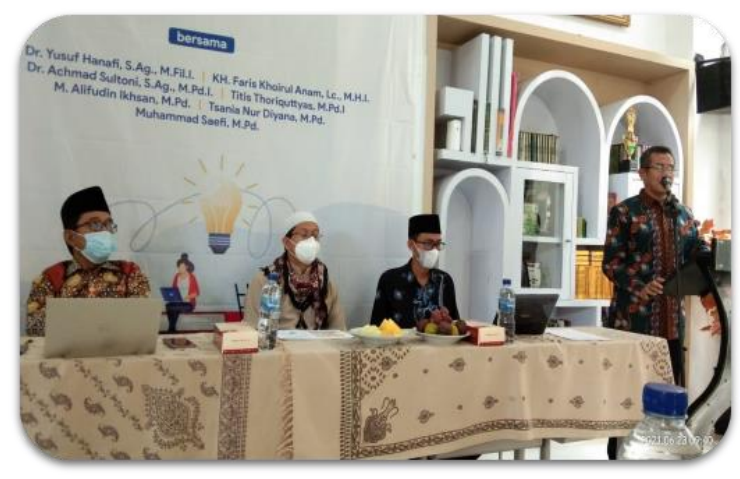

Gambar 3. Para narasumber menyampaikan paparan

Sekolah berbasis PE menjadi bagian dari pencegahan sifat dan karakter radikal pada diri peserta didik. Fenomena radikalisasi agama di Indonesia hingga hari ini masih menjadi perbincangan yang menarik dan terus menghangat. Radikalisme masih menjadi masalah serius bagi banyak kalangan termasuk pemerintah. Munculnya isu-isu mengenai radikalisme agama merupakan tantangan baru yang harus diselesaikan. Isu radikalisme Islam juga mencuat di perbincangan internasional. Radikalisme Islam sebagai fenomena 
historis-sosiologis merupakan masalah yang banyak dibicarakan dalam wacana politik dan peradaban global akibat kekuatan media dalam menciptakan persepsi masyarakat. Banyak label yang diberikan oleh dunia, khususnya Amerika Serikat untuk menyebut gerakan Islam radikal ini, mulai dari sebutan kelompok garis keras, ekstrimis, militan, Islam kanan, fundamentalis sampai teroris.

Pandangan barat tersebut menjadikan Islam sebagai agama yang eksklusif bagi warga internasional. Dalam perkembangannya, kini umat Islam sering diperlakukan tidak adil di negara-negara dengan mayoritas penduduk non-muslim. Dari sifat eksklusifitas tersebut, muncullah berbagai akar sejarah radikalisme di Indonesia. Pada mulanya, radikalisme dilakukan untuk menentang kolonialisme. Namun dalam perkembangannya, radikalisme yang berkembang di kalangan generasi muda, kini bertujuan untuk menentang negara dan falsafah bangsa. Islam merupakan agama damai yang mengajarkan perdamaian. Sementara yang dimaksud dengan radikalisme adalah gerakan yang berpandangan keras dan kaku dalam menanggapi berbagai problematika kehidupan modern.

Berbagai pihak menganggap bahwa kekerasan atas nama agama oleh siswa SMP di atas diakibatkan karena ekstrimnya pemahaman siswa dan guru terhadap mata pelajaran Pendidikan Agama di sekolah. Padahal agama, khususnya Islam menekankan moderatisme, inklusivitas, dan toleransi yang termaktub dalam Al-Quran (Hanafi \& Ikhsan, 2019; Ikhsan, 2017b, 2019), seperti perlindungan hak asasi manusia, kebebasan beragama, kesetaraan dan peluang yang setara untuk hak asasi manusia dalam masyarakat sipil (Yesilova, 2010). UNESCO (1996) juga mendefinisikan toleransi sebagai kebajikan yang memungkinkan perdamaian dan berkontribusi pada penggantian budaya perang dengan budaya perdamaian. Toleransi adalah harmoni dalam perbedaan, diterjemahkan dalam semboyan negara Indonesia yakni Bhinneka Tunggal Ika. Sangat jelas, bahwa toleransi agama Islam sejalan dengan Pancasila, maka dari itu konsep sekolah berbasis PE adalah langkah tepat dalam menekan radikalisme di lingkungan sekolah.

Dalam konteks ini, untuk mengeliminasi terbentuknya kelompok keagamaan yang eksklusif di sekolah sebagai cikal bakal radikalisme, tim pengabdian kepada masyarakat Universitas Negeri Malang (UM) mengambil peran sebagai fasilitator dan pembimbing, yaitu membantu sekolah menuju proses ke arah kedewasaan lembaga dan sistem sehingga dapat saling menghargai perbedaan yang ada di dalam dan di sekitar lingkungan sekolah (Abdullah \& Yani, 2009). Sekolah memiliki peran sentral dalam mengawal moderasi beragama. Revitalisasi peran sekolah untuk menguatkan kajian akidah, tasawuf dan fiqih sosial yang mengakomodasi paham moderat menjadi penting untuk dilakukan. Sejumlah penelitian yang telah dilakukan telah membuktikan bahwa pesantren pada umumnya lebih memfokuskan diri pada salah satu aspek ilmu syariat, yaitu ilmu fiqih (figh oriented) dimana orientasi muatan fiqih lebih mendominasi, terpola, dan sistemik (Amirudin, 2017; Labiba, 2021; Rifa'i et al., 2017). 


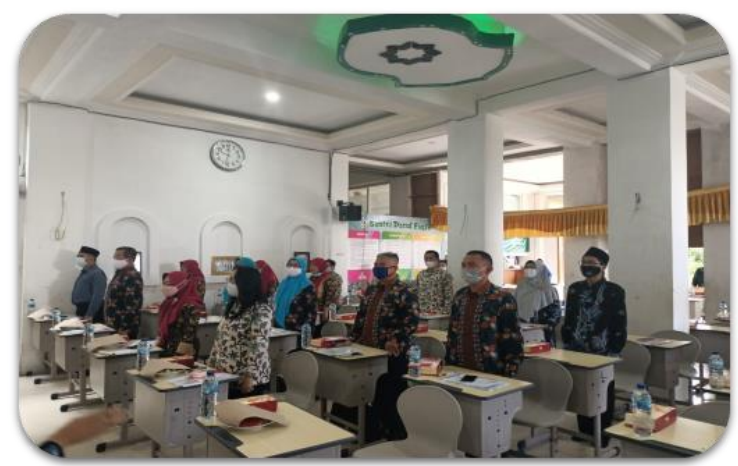

Gambar 4. Kegiatan diskusi oleh para kepala sekolah dan wakil kepala sekolah bidang kurikulum

Berdasarkan hasil FGD pada sesi kedua dalam kegiatan edukasi ini, upaya yang dilakukan oleh kepala sekolah, wakil kepala sekolah, dan guru untuk mengimplementasikan sekolah berbasis PE diringkas sebagai berikut. (1) Atmosfer dan budaya sekolah; Toleransi sesama guru, sesama siswa, dan antara guru dan siswa menjadi hal yang paling utama. Seluruh warga sekolah diberikan kebebasan dalam menjalankan ibadah sesuai kepercayaan. (2) Kebiasaan (behaviour) yang dilakukan oleh kepala sekolah dan guru. Membudayakan salam, sapa, dan senyum kepada seluruh warga sekolah dan mendorong siswa maupun guru untuk berekspresi dan mengungkapkan pendapatnya. (3) Apresiasi budaya yang berbeda; Mendorong siswa untuk mengenal budaya sendiri, teman, dan guru mereka. Selain itu, juga dilakukan diskusi antar siswa dan guru tentang kerukunan antar umat beragama. (4) Resolusi konflik; Pertama, dilakukan pendekatan pribadi terhadap individu yang bermasalah untuk mencari informasi lebih mendalam. Kedua, melakukan mediasi. Ketiga, musyawarah, mufakat, dan mencari jalan keluar yang bersumber pada aturan agama dan hukum yang berlaku. (5) Partisipasi aktif dan kolaboratif. Mendorong siswa untuk mau bekerjasama dalam kelompok yang heterogen. Guru menerapkan pembelajaran aktif, menyenangkan, dan berjalan dua arah. (6) Sikap toleransi; Membiasakan siswa dan guru untuk melakukan kegiatan sosial bersama, mematuhi aturan sekolah, dan melakukan edukasi tentang pelarangan dan bahaya bullying di sekolah. (7) Eksklusivitas di sekolah dengan cara Memfilter bahan bacaan yang masuk kedalam sekolah, dan mendorong semua siswa untuk saling berbaur. (8) Nilai agama dalam kehidupan sekolah. Agama menjadi nilai penting dan utama, di sekolah perwujudannya dapat berupa berdo'a di awal dan di akhir pembelajaran dan integrasi nilai agama dalam pembelajaran. 


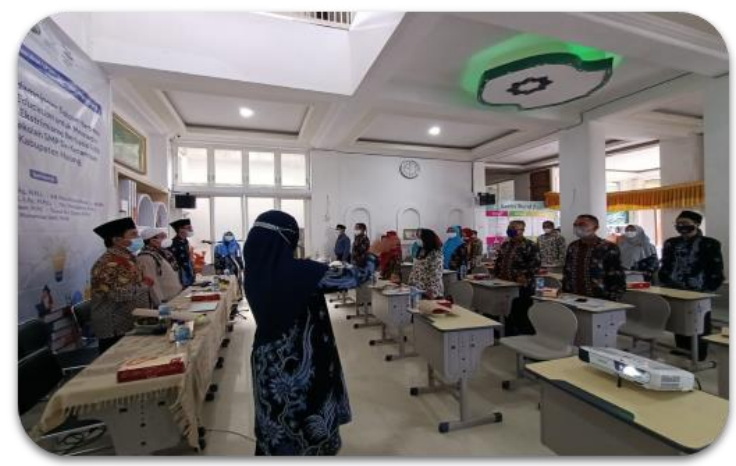

Gambar 5. Peserta kegiatan

Adapun implikasi atas kegiatan pengabdian kepada masyarakat ini menyangkut beberapa aspek penting diantaranya adalah kesadaran sekolah tentang pentingnya pendidikan budaya damai di sekolah, lahirnya beberapa peraturan dan kebijakan sekolah terkait PE serta tersosialisasinya toleransi dan semangat keberagaman kepada para siswa. Dari 8 sekolah yang menjadi sasaran implementasi program, 5 sekolah telah menghasilkan kebijakan penerapan PE di lingkungan sekolah diantaranya SMP Darul Faqih Indonesia, SMP Kristen Eleos, SMP Negeri 1 Wagir, SMP Islam Sunan Giri dan SMP PGRI 1 Wagir. Kebijakan sekolah ini menyangkut program kegiatan sekolah tentang sosialisasi dan implementasi kegiatan PE. PE dimaknai sebagai kegiatan berkesinambungan yang melibatkan siswa, guru dan lingkungan belajar.

Dampak kegiatan pengabdian ini juga mampu merubah stigma guru tentang pembelajaran dan cara mengajar siswa tentang toleransi. Guru yang biasanya hanya menjelaskan dan memaparkan PE dengan teori kini mampu memberikan pendidikan PE secara langsung dengan cara mengikuti program sosialisasi dan edukasi bersama sekolah lain. Siswa juga dapat berinteraksi dengan beragam agama yang ada di sekitar mereka. Pembelajaran seperti ini akan memberikan lesson learn yang baik untuk pengalaman hidup para siswa.

Selain itu, metode pembelajaran mempunyai peranan penting dalam meningkatkan wawasan kebangsaan dan keagamaan peserta didik, terutama karena guru dianggap sebagai sumber pengetahuan agama paling utama dan paling bertanggung jawab untuk membantu peserta didik dalam mengembangkan kesadaran spiritual dan moral (Halstead, 2004). Kasim \& Yusoff (2014) mengemukakan bahwa guru dapat menggunakan berbagai metode pembelajaran untuk merangsang minat peserta didik pada konsep spiritual dan moral dan untuk menginspirasi mereka untuk memasukkan nilainilai kebangsaan dan keagamaan dalam pendidikan dan pertumbuhan pribadi mereka. Saeed (1999) menyarankan untuk menerapkan metode pengajaran dengan menutup kesenjangan antara agama dan praktik-praktiknya yang valid dengan memberikan peserta didik kebebasan untuk mengeksplorasi dan mendiskusikan ide-ide, menciptakan suasana terbuka untuk berpikir.

Metode pengajaran seperti itu penting bagi peserta didik untuk memahami bahwa nila-nilai keagamaan sejalan dengan nilai-nilai kebangsaan, 
lebih jelas bahwa Islam dan Pancasila adalah dua hal yang tidak perlu dipertentangkan. Pendekatan konseptual sekolah berbasis peace culture education dapat menjadi sebuah solusi untuk mencabut akar penyebab radikalisme yang semakin kompleks, dan seharusnya diprioritaskan dalam dialog agama dan kebangsaan (Mahfud et al., 2018). Fokus dari metode pengajaran ini adalah menyadarkan peserta didik bahwa radikalisme tidak sesuai dengan ajaran agama sehingga mereka harus mengetahui perkembangan radikalisme, bahaya, dan cara-cara menanggulanginya melalui kegiatan diskusi. Untuk semakin memperkuat sikap dan jiwa moderat siswa, pihak sekolah dan guru diharapkan memberikan dukungan dan wadah yang tepat bagi peserta didik dengan mendukung organisasi yang mengedepankan faham Islam moderat, untuk menyelenggarakan dengan menyelenggarakan kajian Islam yang bersifat moderat dan diskusi kebangsaan kepada siswa baik di dalam maupun di luar kelas. Berikut merupakan diagram alur program dan implikasi kegiatan pengabdian kepada masyarakat yang telah dilakukan.
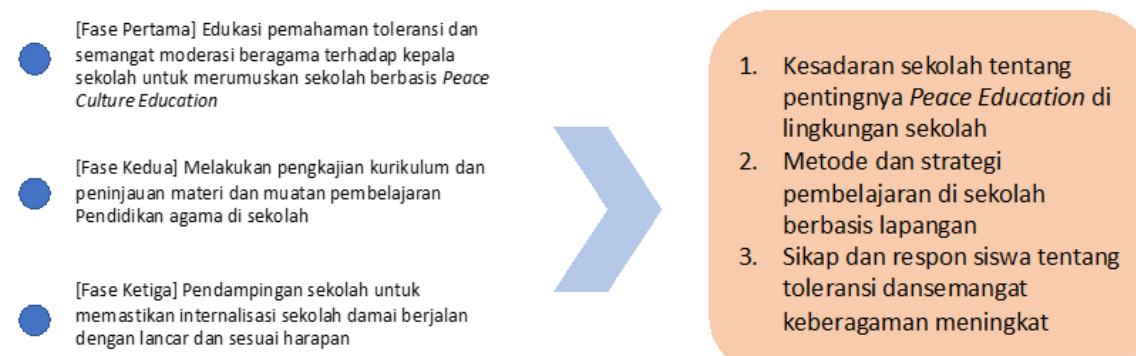

Gambar 6. Peta konsep implikasi kegiatan

\section{KESIMPULAN}

Radikalisme tidak bisa dilepaskan dari pemahaman seseorang terhadap agamanya. Penelitian pendahuluan di atas menunjukkan bahwa terdapat potensi pemikiran radikal beragama yang mampu memberikan dampak negatif bagi eksistensi negara. Pemerintah telah melakukan tindakan tegas dengan membubarkan ormas-ormas Islam yang dianggap radikal baik pemikiran maupun tindakannya. Sikap radikal sebenarnya tidak serta-merta muncul saat seseorang beranjak dewasa, tetapi bibit radikalisme tersebut sebenarnya telah ada sejak di bangku sekolah dasar.

Edukasi sekolah berbasis PE ini telah membantu untuk memberikan pemahaman kepada kepala sekolah dan guru serta keyakinan mereka dalam mengimplementasikan nilai-nilai perdamaian, tindakan tanpa kekerasan, semangat untuk hidup berdampingan antar umat beragama, menerapkan sikap toleransi, dan bersedia untuk membuat resolusi konflik. Program ini dirancang melalui serangkaian kegiatan mulai dari seminar, FGD, dan kedepan menargetkan pelaksanaan lebih nyata di kelas. Program pendidikan damai ini telah dilaksanakan melalui kemitraan MKKS Sub Rayon 33 Wagir dengan melibatkan delapan SMP target di Kecamatan Wagir. Edukasi ini menggunakan pendekatan partisipatif dan kolaboratif yang difasilitasi oleh tim pengabdian kepada masyarakat Universitas Negeri Malang (UM). 
Dalam refleksi, terdapat dua faktor yang mempengaruhi kesuksesan edukasi ini. Pertama, wacana dan implementasi sekolah berbasis PE belum melibatkan guru agama. Keterlibatan mereka sangat dibutuhkan khususnya implementasi kepada siswa dalam pembelajaran di kelas. Kedua, buku pegangan yang berisikan landasan dan langkah-langkah yang memandu guru dan siswa dalam mengimplementasikan sekolah berbasis PE dinilai masih minim ketersediaannya. Adapun implikasi yang diperoleh dari kegiatan ini setidaknya terdapat dua hal penting yakni sekolah menjadi sadar akan pentingnya pendidikan budaya damai diterapkan di lingkungannya serta meningkatkan kepekaan dan kesadaran siswa tentang pentingnya toleransi dan semangat keberagaman. Kedepan, bentuk sekolah berbasis PE ini juga perlu dikembangkan di tingkat lain, tidak hanya di SMP dan sederajat, namun juga untuk tingkat SD dan SMA, bahkan perguruan tinggi. Selain itu, pengembangan buku pegangan perlu disediakan lebih luas lagi dalam bentuk digital.

\section{UCAPAN TERIMAKASIH}

Kami sangat berterima kasih kepada Lembaga Penelitian dan Pengabdidan Masyarakat (LP2M) Universitas Negeri Malang (UM) yang telah memberikan pendanaan dan SMP Darul Faqih Indonesia (DFI) Malang sebagai mitra dalam pelaksanaan kegiatan pengabdian masyarakat ini. Terimakasih juga disampaikan kepada Majelis MKKS (Musyawarah Kerja Kepala Sekolah) Sub Rayon 33 Wagir Kabupaten Malang atas dukungan yang diberikan kepada tim pengabdian masyarakat UM untuk melaksanakan edukasi dan pendampingan sekolah berbasis peace culture education.

\section{DAFTAR RUJUKAN}

Abdullah, M. H., \& Yani, M. T. (2009). Wacana Islam Inklusif dalam Kuliah Pendidikan Agama Islam di Perguruan Tinggi Umum. Nadwa: Jurnal Pendidikan Islam (Islamic Education Journal), 3(1).

Al-Zewairi, M., \& Naymat, G. (2017). Spotting the Islamist Radical within: Religious Extremists Profiling in the United State. Procedia Computer Science, 113, 162-169. https://doi.org/10.1016/j.procs.2017.08.336

Amirudin, Y. (2017). Pendidikan Karakter Berbasis Nilai-Nilai Aswaja. Vicratina: Jurnal Pendidikan Islam, 2(2), 109-120.

http://riset.unisma.ac.id/index.php/fai/article/view/4873

Ariyanto, Pangaribuan, R. M., \& Ginting, K. B. (2019). Konstruksi Dan Analisis Model Matematika Radikalisme. Jurnal Komputer Dan Informatika, 7(2), 96-101. https://doi.org/10.35508/jicon.v7i2.1683

Fathurrochman, I., Ristianti, D. H., \& Arif, M. A. S. bin M. (2019). Revitalization of Islamic Boarding School Management to Foster the Spirit of Islamic Moderation in Indonesia. Jurnal Pendidikan Islam, 8(2), 239-258. https://doi.org/10.14421/jpi.2019.82.239-258

Halstead, M. (2004). An Islamic concept of education. Comparative Education, 40(4), 517-529. https://doi.org/10.1080/0305006042000284510

Hanafi, Y., \& Ikhsan, M. A. (2019). Prosecuting The House of God: The Irony of Rights to Freedom of Worship for Dhimmi Minority in Indonesia. Justicia 
Islamica, 16(1), 1-20. https://doi.org/10.21154/justicia.v16i1.1535

Hermawan, M. A. (2015). Islam Inklusif dalam Kurikulum Pendidikan Agama Islam SLTA. Jurnal Penelitian Agama, 16(2), 180-198. https://doi.org/10.24090/jpa.v16i2.2015.pp180-198

Ibrahim, I., Wulansari, D., \& Hidayat, N. (2018). Radicalism in Indonesia and the Reflective Alternatives to Reduce. PEOPLE: International Journal of Social Sciences, 3(3), 1554-1564. https://doi.org/10.20319/pijss.2018.33.15541564

Ikhsan, M. A. (2017a). Fiqih HAM dan Hak Kebebasan Beribadah Minoritas Dzimmi Di Indonesia. Jurnal Ilmiah Pendidikan Pancasila Dan Kewarganegaraan, 2(1), 34-40. https://doi.org/10.17977/um019v2i12017p034

Ikhsan, M. A. (2017b). Nilai - Nilai Cinta Tanah Air Dalam Perspektif Al-Qur'an. Jurnal IImiah Pendidikan Pancasila Dan Kewarganegaraan, 2(2), 108114. https://doi.org/10.17977/um019v2i22017p108

Ikhsan, M. A. (2019). Al-Quran dan Deradikalisasi Paham Keagamaan di Perguruan Tinggi: Pengarusutamaan Islam Wasathiyah. Jurnal IImu Al Qur'an Dan Hadis, 2(2), 98-112. https://doi.org/10.35132/albayan.v2i2.71

Kasim, T. S. A. T., \& Yusoff, Y. M. (2014). Active Teaching Methods: Personal Experience of Integrating Spiritual and Moral Values. Religious Education, 109(5), 554-570. https://doi.org/10.1080/00344087.2014.956560

Labiba, S. (2021). Pembelajaran Aswaja Untuk Menangkal Paham Radikalisme intoleran Pada Peserta Didik di MA Maarif Al-Asy`ari Ranggeh Pasuruan. Turatsuna: Jurnal Keislaman Dan Pendidikan, 3(1), 122-138. http://riset.unisma.ac.id/index.php/TRSN/article/view/10026

Llorent-Bedmar, V., Palma, V. C. C.-D., \& Navarro-Granados, M. (2020). Islamic religion teacher training in Spain: Implications for preventing islamicinspired violent radicalism. Teaching and Teacher Education Journal, 95, 1-12. https://doi.org/10.1016/j.tate.2020.103138

Lue, M. ., \& Riyanto, K. B. (2020). Multicultural Social Peaceful Education through Social Guidance and Counseling Services in Development of Industrial Revolution 4.0. The 2nd International Seminar on Guidance and Counseling 2019 (ISGC 2019), 241-245. https://doi.org/10.2991/assehr.k.200814.052

Mahfud, C., Prasetyawati, N., Muhibbin, Z., \& Agustin, D. S. Y. (2018). Religious Radicalism , Global Terrorism and Islamic Challenges in Contemporary Indonesia. Jurnal Sosial Humaniora (JSH), 11(1), 8-18. https://doi.org/10.12962/j24433527.v11i1.3550

Maskuri, Ma'arif, A. S., \& Fanan, M. A. (2020). Mengembangkan Moderasi Beragama Mahasantri Melalui Ta'lim Ma'hadi di Pesantren Mahasiswa. JPAl: Jurnal Pendidikan Agama Islam, 7(1), 32-45. https://doi.org/10.18860/jpai.v7i1.11239

Rifa'i, A., WP, S. D., \& Alimi, M. Y. (2017). Pembentukan Karakter Nasionalisme melalui Pembelajaran Pendidikan Aswaja pada Siswa Madrasah Aliyah Al Asror Semarang. Journal of Educational Social Studies, 6(1), 7-19. https://doi.org/10.15294/jess.v6i1.16250 
Saeed, A. (1999). Towards religious tolerance through reform in Islamic education: The case of the state institute of Islamic studies of Indonesia. Indonesia and the Malay World, 27(79), 177-191. https://doi.org/10.1080/13639819908729941

Saidi, A. (2017, July 18). Radikalisme di Kalangan Mahasiswa sudah Mengkhawatirkan. Lipi.Go.ld. http://lipi.go.id/lipimedia/radikalisme-dikalangan-mahasiswa-sudah-mengkhawatirkan/18630

Thoyib, M. (2018). Pesantren and Peace Education Development: Challenges, Strategies and Contribution to Deradicalization in Indonesia. MADINA: Jurnal Kajian Keislaman, 22(2), 225-238. https://doi.org/10.29300/madania.v22i2.1174

UNESCO. (1996). Declaration of Principles on Tolerance. https://en.unesco.org/commemorations/toleranceday

Yesilova, H. (2010). Justice, Human Rights, and the Quasi-Civil Society in a Muslim Context. European Journal of Economic and Political Studies, 3(2), 127-144. 